\title{
Potassium exchange in the human heart during atrial pacing and myocardial ischaemia
}

\author{
STUART C WEBB, PHILIP A POOLE-WILSON \\ From the Cardiothoracic Institute and National Heart Hospital, London
}

SUMMARY Potassium homoeostasis in the heart was studied during atrial pacing in 20 patients undergoing diagnostic coronary angiography. The potassium concentrations in the coronary sinus and a systemic artery were recorded continuously by means of catheter tip potassium electrodes. Ten patients with coronary artery disease and a positive exercise test developed chest pain and ST segment depression on the electrocardiogram during atrial pacing. Potassium concentrations in the coronary sinus rose initially and increased further when myocardial ischaemia developed. Ten patients including five with normal coronary arteries remained symptom free during atrial pacing with no electrocardiographic changes. In these patients coronary sinus potassium concentration increased at the onset of pacing, but returned to near control values despite continued pacing. In both groups arterial potassium concentration remained constant. Immediately after the end of pacing there was an abrupt transient fall in potassium concentrations in the coronary sinus to below control values.

These results indicate that in man, as in other species, an increase in heart rate causes the transient movement of potassium out of the cell into the extracellular space. The onset of myocardial ischaemia is associated with a further loss of potassium from the cell. The end of pacing or ischaemia is accompanied by a re-uptake of potassium by heart muscle.

Potassium loss by the ischaemic myocardium has been known for over 30 years. ${ }^{1}$ More recently, in vivo recordings with ion selective electrodes have shown that within seconds of the interruption of coronary arterial perfusion extracellular potassium accumulates in the myocardium ${ }^{2-4}$ and coronary sinus potassium concentration $\left(\left[\mathrm{K}^{+}\right]\right)$increases in animals ${ }^{2}$ and man. ${ }^{5}$ The increase in extracellular $\left[\mathrm{K}^{+}\right]$can account for the reduction in resting membrane potential and conduction velocity recorded during early ischaemia, ${ }^{6}$ and may contribute to changes in action potential morphology. Such observations suggest that monitoring myocardial potassium balance may be a sensitive means of detecting the onset of myocardial ischaemia in patients and that potassium loss may be an important factor in initiating early arrhythmias. ${ }^{6}$

Previous attempts to investigate myocardial potassium exchange in man have been limited to the

Requests for reprints to Professor P A Poole-Wilson, The Cardiothoracic Institute, 2 Beaumont Street, London W1N 2DX.

Accepted for publication 24 February 1986 analysis of multiple samples of arterial and coronary sinus blood obtained during pacing induced myocardial ischaemia. ${ }^{78}$ Loss of myocardial potassium is evident under these conditions, but may be attributed in part to the effects of increasing heart rate ${ }^{7}$ rather than to the onset of ischaemia.

In order to differentiate between the effects of heart rate and ischaemia on myocardial potassium balance we have used ion selective intravascular electrodes to obtain continuous recordings of arterial and coronary sinus $\left[\mathrm{K}^{+}\right]$. We compared the effects of incremental atrial pacing on the coronary arteriovenous $\left[\mathrm{K}^{+}\right]$gradient in two groups of patients undergoing investigation of effort related chest pain. Patients in one group developed angina and changes on the electrocardiogram during pacing while patients in the other group did not.

\section{Patients and methods}

Twenty subjects were selected from patients undergoing diagnostic coronary angiography for the investigation of effort related chest pain. Thirteen 
were male and the mean age was 49 years. Patients with recent myocardial infarction, left ventricular aneurysm, or chest pain at rest were excluded. All patients underwent treadmill exercise testing before investigation and were in sinus rhythm with no conduction abnormalities or evidence of any cardiac pathology other than ischaemic heart disease. No patients were taking digoxin and all antianginal medication other than sublingual nitrates were discontinued for at least 24 hours before the study. Written informed consent was obtained in all cases. The study was approved by the ethical committee of the National Heart and Chest Hospitals.

\section{POTASSIUM ELECTRODES}

Catheter tip electrodes for monitoring intravascular ion concentrations have been described elsewhere. ${ }^{5910}$ Those used in this study were sterilised by immersion in aqueous glutaraldehyde and detected changes in $\mathrm{K}^{+}$activity over the range $2-32$ $\mathrm{mmol} / \mathrm{l}$ with a response time of less than $800 \mathrm{~ms}$. No interference occurred from other ions. For intravascular recording, an electrode was passed through the lumen of a size 8 French gauge thin walled Cournand catheter (USCI) via a sliding $\mathrm{Y}$ connector. The catheter was continuously flushed through the second branch of the $\mathrm{Y}$ connector with physiological saline containing $4 \mathrm{mmol} / 1$ potassium chloride by means of a pressurised system (CFS Intraflo, Sorenson Research, Salt Lake City, Utah) to prevent reflux of blood. A calomel reference electrode (K4112, Radiometer, Copenhagen) was connected to the flush line by a $\mathrm{T}$ piece, thereby maintaining electrical contact with the patient's blood through the column of saline in the catheter surrounding the $\mathrm{K}^{+}$electrode. The potential difference between the electrode and the reference was recorded by means of an optically isolated amplifier (3650 HG, Burr-Brown, Tucson, Arizona) and a twin channel pen recorder (3559 and MX2, Devices, Welwyn Garden City).

The potassium electrodes were calibrated before and after clinical use by immersion in a series of solutions of known concentration of potassium chloride in physiological saline at $37^{\circ} \mathrm{C}$. Plasma $\left[\mathrm{K}^{+}\right]$was determined at the start of each study by photometric analysis of a sample of blood aspirated from the recording site. Subsequent variations in plasma $\left[\mathrm{K}^{+}\right]$were calculated fom the electrical signal by reference to the calibration curve. Results were expressed as mean (1 SE) and analysed by Student's $t$ test.

\section{PACING PROTOCOL}

One hour after premedication with lorazepam (1-2 mg orally) the Cournand catheter was inserted via the left subclavian vein (infraclavicular approach) and positioned with its tip $4 \mathrm{~cm}$ into the coronary sinus. Its position was checked by injection of contrast medium and the control sample of coronary

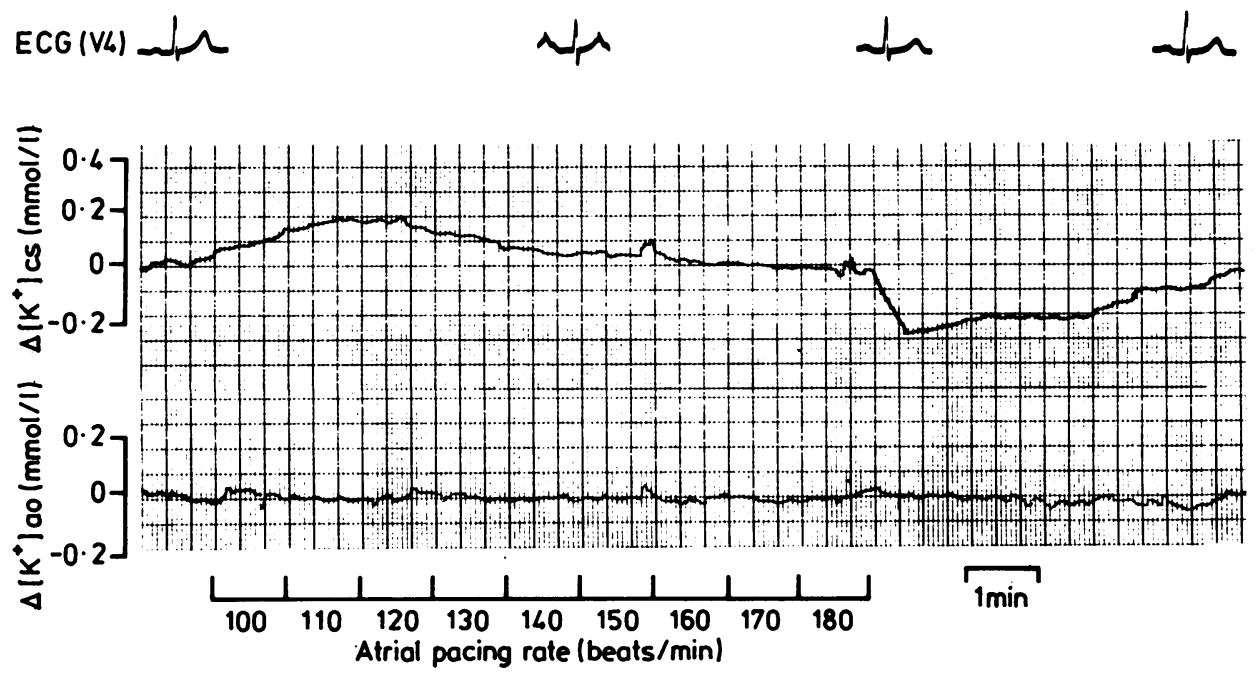

Fig. 1 Simultaneous recordings of coronary sinus and arterial potassium concentration $\left(\left[\mathrm{K}^{+}\right] \mathrm{cs}\right.$ and $\left.\left[K^{+}\right] a o\right)$ before, during, and after a 9 min period of incremental atrial pacing in a patient in the non-ischaemia group. $\left[\mathrm{K}^{+}\right]$ao remained constant throughout, but $\left[\mathrm{K}^{+}\right]$cs rose initially before declining to near pre-pacing levels by the end of the test. After the end of pacing, $\left[\mathrm{K}^{+}\right] \mathrm{cs}$ fell rapidly and remained at subnormal levels for 4 min. No ST segment depression occurred in any electrocardiographic lead (V4 displayed). 


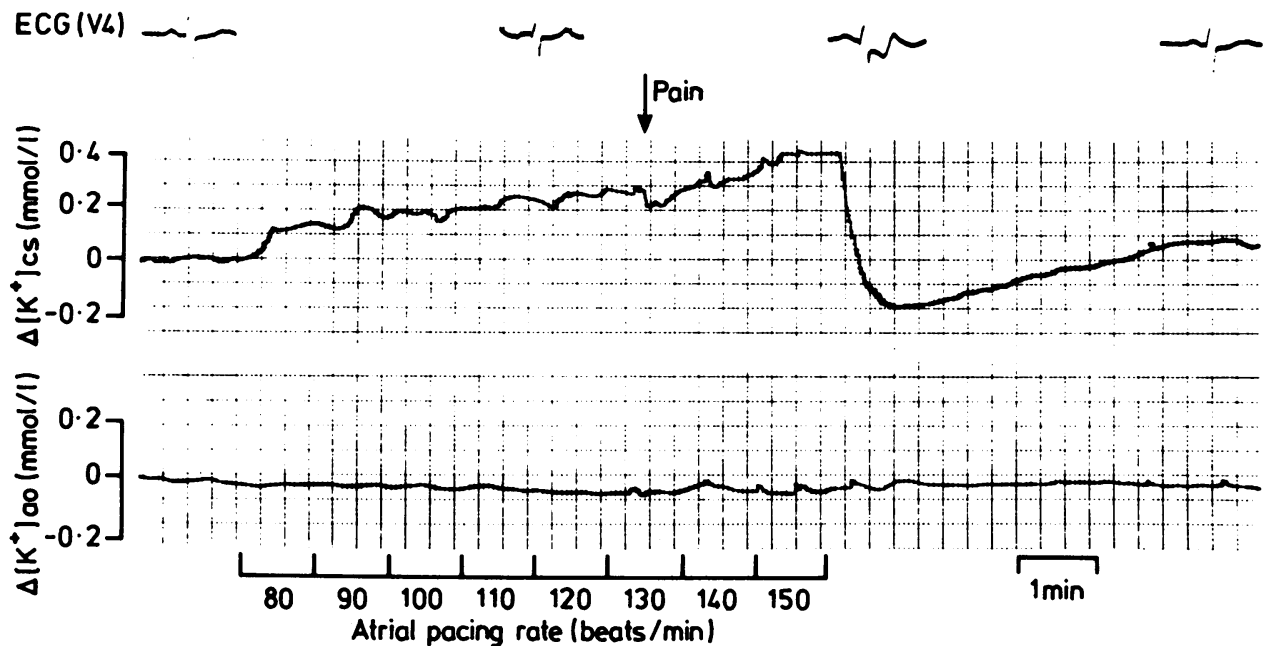

Fig. 2 Experimental record from a patient in the ischaemic group who developed chest pain and $S T$ segment depression (maximal in lead V4) during incremental atrial pacing. There was little change in arterial potassium concentration $\left(\left[\mathrm{K}^{+}\right]\right.$ao $)$but coronary sinus potassium concentration $\left(\left[\mathrm{K}^{+}\right] \mathrm{cs}\right)$ rose throughout the test reaching a maximum of $0.4 \mathrm{mmol} / \mathrm{l}$ above pre-pacing levels. $\left[\mathrm{K}^{+}\right] \mathrm{cs}$ fell rapidly after the end of pacing and remained at subnormal levels for 3 min.

sinus blood was obtained. A potassium electrode was introduced until its tip protruded into the coronary sinus near the origin of the anterior cardiac vein. An arterial catheter was inserted through a right brachial arteriotomy or direct puncture of the femoral artery. In 14 patients continuous recordings were made of left ventricular pressure during pacing. In the remaining six a second Cournand catheter and potassium electrode were used to record arterial $\left[\mathrm{K}^{+}\right]$in either the descending aorta or subclavian artery.

A size 5 French gauge temporary pacemaker electrode was sited in the right atrium and connected to an impulse generator (Devices). After a 10 min equilibration period the patient's heart rate was measured and an atrial pacing test was performed. The initial pacing rate was 10 beats/min above sinus rate and was increased by 10 beats/min every minute. Technically satisfactory recordings of coronary sinus $\left[\mathrm{K}^{+}\right](\mathrm{n}=19)$, arterial $\left[\mathrm{K}^{+}\right](\mathrm{n}=6), 12$ lead surface electrocardiogram $(n=20)$, and left ventricular end diastolic pressure $(n=12)$ were obtained. The test was terminated if the patient complained of increasing chest pain accompanied by ST segment depression $>3 \mathrm{~mm}$ in any lead, if atrioventricular block developed, or if a maximum heart rate of 180 beats/min was attained. Recording was continued after the end of pacing for at least $3 \mathrm{~min}$. Left ventriculography and coronary angiography were performed subsequently.

\section{Results}

Two groups of patients were defined on the basis of their clinical and electrocardiographic response to atrial pacing.

\section{NON-ISCHAEMIC GROUP}

In 10 patients no electrocardiographic changes developed and they either remained symptom free $(n=8)$ or complained of mild chest discomfort $(n=2)$ during atrial pacing. Five of these patients were assessed as having normal coronary arteries or a reduction in coronary artery diameter of $<50 \%$. Five patients had important coronary artery disease with a stenosis of $\geqslant 50 \%$ in one or more coronary arteries. The failure to induce evidence of ischaemia in this latter subgroup was reflected by negative treadmill exercise testing in three patients. In one patient atrioventricular block developed after 150 beats/min so that the increase of heart rate may have been inadequate to induce ischaemia. In one patient the exercise test was positive, but no evidence of ischaemia was obtained during pacing at 180 beats $/ \mathrm{min}$.

Figure 1 shows a typical recording of changes in arterial and coronary sinus $\left[\mathrm{K}^{+}\right]$during incremental pacing from a patient in this group. Coronary sinus $\left[\mathrm{K}^{+}\right]$began to rise $10 \mathrm{~s}$ after the onset of pacing and reached $0.18 \mathrm{mmol} / 1$ above control after $2 \mathrm{~min}$. With continuing increments in heart rate, $\left[\mathrm{K}^{+}\right]$declined 


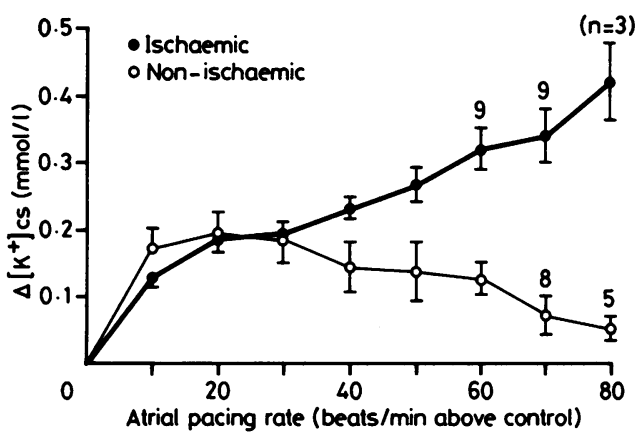

Fig. 3 Comparison of mean changes in coronary sinus $\left[\mathrm{K}^{+}\right]$ at the end of each pacing stage in the ischaemic and non-ischaemic groups. Though a similar rise in $\left[\mathrm{K}^{+}\right]$was found in both groups when the heart rate was increased by 10 and 20 beats/min, the subsequent fall during continued pacing at higher rates in the non-ischaemic group contrasted with the continuing rise in patients who developed ischaemia. Except where indicated there were nine patients in the non-ischaemic group and 10 in the ischaemic group.

and was no longer raised above control at a final heart rate of 180 beats $/ \mathrm{min}$. At the end of pacing, coronary sinus $\left[\mathrm{K}^{+}\right]$fell transiently below the control value by $0.23 \mathrm{mmol} / 1$ before slowly rising to the pre-pacing value over the next $4 \mathrm{~min}$. There was no significant change in arterial $\left[\mathrm{K}^{+}\right]$.

\section{ISCHAEMIC GROUP}

This group consisted of 10 patients whose atrial pacing tests were terminated by the development of chest pain accompanied by ST segment depression $>1 \mathrm{~mm}$ at $80 \mathrm{~ms}$ after the J point in at least one of the anterior chest leads of the electrocardiogram. All patients were found to have important coronary artery disease ( $\geqslant 50 \%$ stenosis in at least one vessel) and had positive treadmill exercise tests. All patients had disease of the left anterior descending coronary artery. Five patients had three vessel disease, four had two vessel disease, and one had single vessel disease.

Figure 2 shows an example of the changes in coro- nary sinus and arterial $\left[\mathrm{K}^{+}\right]$during atrial pacing in one patient from this group. An increase in coronary sinus $\left[\mathrm{K}^{+}\right]$was evident within $20 \mathrm{~s}$ of the start of pacing, and this rise continued throughout the test to reach a peak of $0.42 \mathrm{mmol} / 1$ above control at a maximum heart rate of 150 beats $/ \mathrm{min}$. Chest pain and ST segment depression were first noted at a heart rate of 130 beats/min and were accompanied by an increase in the rate of rise of coronary sinus $\left[\mathrm{K}^{+}\right]$. At the end of pacing there was an abrupt transient fall in coronary sinus $\left[\mathrm{K}^{+}\right]$to a trough of 0.18 $\mathrm{mmol} / \mathrm{l}$ below pre-pacing levels. There was no appreciable change in arterial $\left[\mathrm{K}^{+}\right]$.

\section{COMPARISON OF RESULTS}

Measurements of coronary sinus $\left[\mathrm{K}^{+}\right]$at the end of each incremental pacing stage were taken from a total of 19 continuous recordings obtained from patients in the two groups (arterial $\left[\mathrm{K}^{+}\right]$alone was recorded in one patient in the non-ischaemic group). Figure 3 shows the results, expressed as the change in $\left[\mathrm{K}^{+}\right]$compared with pre-pacing concentrations. Because arterial $\left[\mathrm{K}^{+}\right]$remained constant throughout the test in both ischaemic $(n=3)$ and non-ischaemic patients $(n=3)$ (Figs. 1 and 2 ) the differential effects of pacing on myocardial potassium balance in nonischaemic and ischaemic patients could be assessed by direct comparison of the changes in coronary sinus $\left[\mathrm{K}^{+}\right]$.

Both patient groups responded similarly to the onset of atrial pacing, with a rapid rise in coronary sinus $\left[\mathrm{K}^{+}\right]$, indicating loss of potassium from the myocardium. After pacing at 20 beats/min above control, coronary sinus $\left[\mathrm{K}^{+}\right]$had risen by $0.19(0.07)$ $(n=9)$ and $0.17(0.03) \mathrm{mmol} / \mathrm{l}(\mathrm{n}=10)$ in the nonischaemic and ischaemic groups respectively. With continued pacing at higher rates, however, potassium loss increased in those patients who developed evidence of ischaemia and declined in those who did not. At 50 beats $/ \mathrm{min}$ above control, the increases in coronary sinus $\left[\mathrm{K}^{+}\right]$were $0.14(0.04) \mathrm{mmol} / \mathrm{l}(\mathrm{n}=9)$ (non-ischaemic) and $0.26(0.02) \mathrm{mmol} / \mathrm{l}(\mathrm{n}=10)$ (ischaemic) $(p<0.02$ between groups). In those patients who could be paced up to 70 beats $/ \mathrm{min}$ above control, the difference in response became

Table Comparison of the effects of atrial pacing on coronary sinus and arterial $\left[\mathrm{K}^{+}\right]$and left ventricular end diastolic pressure in the non-ischaemic and ischaemic patient groups

\begin{tabular}{|c|c|c|c|c|c|}
\hline & \multirow{2}{*}{$\begin{array}{l}\text { Peak heart rate } \\
\text { (beats/min) }\end{array}$} & \multirow{2}{*}{$\underset{(\mathrm{mmol} / \mathrm{l})}{\Delta\left[\mathrm{K}^{+}\right] \mathrm{cs}}$} & \multirow{2}{*}{$\begin{array}{l}\Delta\left[K^{+}\right] a s \\
(\text { momol } l l)\end{array}$} & \multicolumn{2}{|c|}{$L V E D P(\mathrm{~mm} H g)$} \\
\hline & & & & Pre-pacing & Post-pacing \\
\hline $\begin{array}{l}\text { Non-ischaemic } \\
\text { Ischaemic }\end{array}$ & $\begin{array}{l}161(3.8) \\
144(3.4)\end{array}$ & $\begin{array}{l}+0.08(0.04)(9) \\
+0.40(0.03)(10)\end{array}$ & $\begin{array}{l}-0.01(0.01)(3) \\
-0.01(0.02)(3)\end{array}$ & $\begin{array}{r}9.9(2.1)(5) \\
12.2(2.7)(7)\end{array}$ & $\begin{array}{l}12.0(1.8)(5) \\
18.4(5.0)(7)\end{array}$ \\
\hline
\end{tabular}

Values expressed as mean (SE) (n).

$\Delta\left[\mathrm{K}^{+}\right] \mathrm{cs}$, change in coronary sinus $\left[\mathrm{K}^{+}\right]$at the end of the pacing test compared with pre-pacing values; $\Delta\left[\mathrm{K}^{+}\right]$ao, change in arterial $\left[\mathrm{K}^{+}\right]$ at the end of the pacing test compared with pre-pacing values; LVEDP, left ventricular end diastolic pressure. 


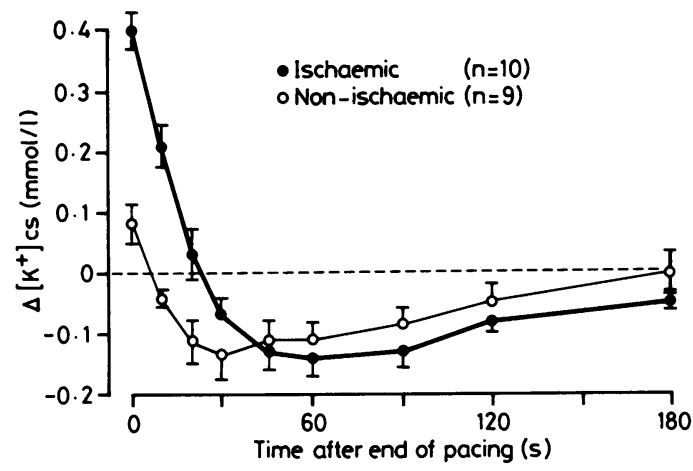

Fig. 4 Comparison of mean changes in coronary sinus $\left[\mathrm{K}^{+}\right]$ recorded at intervals after the end of pacing in the ischaemic and non-ischaemic groups. Results are expressed as changes in $\left[\mathrm{K}^{+}\right]$with respect to the values recorded before the onset of pacing. The phase of subnormal $\left[\mathrm{K}^{+}\right]$(reflecting myocardial potassium uptake) occurred slightly later and persisted longer in the ischaemic patients.

more pronounced. At this rate, coronary sinus $\left[\mathrm{K}^{+}\right]$ had risen by $0.34(0.04) \mathrm{mmol} / 1$ in the presence of ischaemia $(n=9)$ compared with $0.07(0.03) \mathrm{mmol} / 1$ in its absence $(n=8, p<0.001)$. The Table shows the mean values for the changes in coronary sinus and arterial $\left[\mathrm{K}^{+}\right]$at maximal heart rate together with the pre-pacing and post-pacing measurements of left ventricular end diastolic pressure.

After the end of pacing, coronary sinus $\left[\mathrm{K}^{+}\right]$ dropped abruptly in both patient groups and within $30 \mathrm{~s}$ fell below the control levels recorded before pacing (Fig. 4). Because arterial $\left[\mathrm{K}^{+}\right]$did not change (Figs. 1 and 2), this change in coronary sinus $\left[\mathrm{K}^{+}\right]$ represented potassium uptake by the myocardium. In the non-ischaemic group, uptake began within $10 \mathrm{~s}$ of the return to sinus rhythm and was no longer evident after $3 \mathrm{~min}$. Net loss of potassium from the heart persisted for $20 \mathrm{~s}$ in the ischaemic group, and the subsequent uptake was more prolonged, in that coronary sinus $\left[\mathrm{K}^{+}\right]$was still depressed by 0.05 $(0.01) \mathrm{mmol} / 1$ at $3 \mathrm{~min}$.

\section{Discussion}

We have previously demonstrated that intravascular potassium electrodes permit the continuous monitoring of changes in coronary sinus $\left[\mathrm{K}^{+}\right]$during angioplasty ${ }^{5}$ and during coronary arterial injection of solutions rich in potassium. ${ }^{10}$ The technique is capable of detecting small transient changes in myocardial potassium balance by simultaneous recordings of arterial and coronary sinus $\left[\mathrm{K}^{+}\right]$.

In studies on isolated myocardial tissue from various species, an increase in stimulation rate caused a rise in extracellular $\left[\mathrm{K}^{+}\right]$followed by a return to control values. ${ }^{1112}$ The initial loss of intracellular potassium has been attributed to the increased number of action potentials per unit time. Simultaneous accumulation of intracellular sodium is thought to activate the $\mathrm{Na}-\mathrm{K}$ pump, thereby speeding the rate of $\mathrm{K}^{+}$uptake by the cell and restoring the extracellular $\left[\mathrm{K}^{+}\right]$to normal. ${ }^{12}$

Though this mechanism may explain much of the initial rise and subsequent decline in coronary sinus $\left[\mathrm{K}^{+}\right]$observed during pacing in the non-ischaemic group (Fig. 3), changes in myocardial perfusion will have an additional effect. Rapid atrial pacing in the absence of ischaemia is known to cause coronary vasodilatation. ${ }^{1314}$ The consequent increase in coronary blood flow will tend to reduce the magnitude of the change in coronary arteriovenous $\left[\mathrm{K}^{+}\right]$ gradient associated with any given rate of myocardial potassium loss. Though change in myocardial perfusion will also modify coronary sinus $\left[\mathrm{K}^{+}\right]$after the end of pacing, the reversal of the arteriovenous $\left[\mathrm{K}^{+}\right]$gradient that occurs on return to sinus rhythm implies myocardial potassium uptake. This observation is consistent with the theory that increased Na-K pump activity persists for several minutes after restoration of a normal heart rate. ${ }^{1112}$

A different response was seen in patients who developed evidence of ischaemia during the pacing test. The progressive rise in coronary sinus $\left[\mathrm{K}^{+}\right]$ during pacing in the ischaemic group (Fig. 4) can be explained in terms of changes in both myocardial perfusion and potassium efflux from myocardial cells. In the presence of coronary artery disease, the normal rise in regional perfusion during pacing is attenuated and there may even be a reduction in coronary flow distal to a stenosis. ${ }^{1516}$ This may serve to enhance the rise in coronary sinus $\left[\mathrm{K}^{+}\right]$that occurs as a result of both the increase in heart rate and the loss of potassium from ischaemic myocardial tissue. ${ }^{2-4}$ The mechanism of potassium efflux during ischaemia is unknown, ${ }^{17}$ but is probably related to the early intracellular accumulation of permeant negative ions such as lactate and phosphate.

The abrupt fall in coronary sinus $\left[\mathrm{K}^{+}\right]$and transient uptake of myocardial potassium after the end of pacing induced ischaemia can also be accounted for by observations made in animal studies. Early during ischaemia, loss of intracellular potassium is heart rate dependent and the activity (and responsiveness) of the Na-K pump is preserved. ${ }^{618}$ These factors may combine to cause a rapid restoration of normal myocardial potassium balance on return to sinus rhythm.

There is a substantial difference between this pattern of changes of coronary sinus $\left[\mathrm{K}^{+}\right]$and that observed for coronary sinus $\mathrm{pH}$ under similar 
experimental conditions. ${ }^{19}$ Only a minor degree of acidification of the coronary venous effluent occurs during pacing induced ischaemia, but there is a brief, rapid fall in $\mathrm{pH}$ on return to sinus rhythm. This may reflect the fact that whereas potassium lost from myocardial cells will cause a rapid rise in interstitial and hence intravascular $\left[\mathrm{K}^{+}\right]$, hydrogen ions can accumulate (and be buffered) in all tissue compartments. There may then be a relatively greater "load" of hydrogen ions to be "washed out" of the myocardium during the post-ischaemic period.

Previous studies on the effects of rapid atrial pacing in man have been based on analysis of multiple samples of arterial and coronary venous blood. ${ }^{78}$ They have shown a similar overall pattern of changes in myocardial potassium balance to those observed in the current study, but have been unable to determine the time course of events. Contradictory information has been reported regarding the effects of changes in heart rate in the absence of ischaemia. Parker et al showed a transient loss of myocardial potassium after the onset of pacing ${ }^{7}$ whereas Dagenais et al were unable to demonstrate any significant change in myocardial potassium exchange in the absence of ischaemia. ${ }^{8}$ It is likely that the $2 \mathrm{~min}$ sampling interval used in the latter study was responsible for these divergent findings.

Our results demonstrate that the changes in myocardial potassium exchange known to be associated with the onset of ischaemia in animals also occur in man. The electrophysiological consequence of rapid extracellular accumulation of potassium during ischaemia are likely to contribute to changes in the surface electrocardiogram and the genesis of arrhythmias. The technique of continuously monitoring coronary sinus $\left[\mathrm{K}^{+}\right]$provides a sensitive means of detecting the onset of myocardial ischaemia, but the direct effects of any simultaneous change in heart rate must be taken into account.

This work was undertaken during the tenure by SCW of a British Heart Foundation Junior Research Fellowship. We thank Mr R Montgomery for technical assistance.

\section{References}

1 Harris AS, Bisteni A, Russel RA, Brigham JC, Firestone JE. Excitatory factors in ventricular tachycardia resulting from myocardial ischaemia. Potassium a major excitant. Science 1954; 119: 200-3.

2 Hirche H, Franz C, Bös L, Bissig R, Lang R, Schramm M. Myocardial $\mathrm{K}^{+}$and $\mathrm{H}^{+}$increase and noradrenaline release as possible causes of early arrhythmias following acute coronary artery occlusion in pigs. 7 Mol Cell Cardiol 1980; 12: 574-93.

3 Hill JL, Gettes LS. Effect of acute coronary artery occlusion on local myocardial $\mathrm{K}^{+}$activity in swine. Circulation 1980; 61: 768-78.

4 Weiss J, Shine KI. Extracellular $\mathrm{K}^{+}$accumulation during myocardial ischemia in isolated rabbit heart. $A m \boldsymbol{F}$ Physiol 1982; 242: H619-28.

5 Webb SC, Rickards AF, Poole-Wilson PA. Coronary sinus potassium concentration during angioplasty. $\mathrm{Br}$ Heart $\mathcal{F}$ 1983; 50: 146-8.

6 Weiss J, Shine KI. Extracellular $\mathrm{K}^{+}$accumulation during early myocardial ischemia. Implications for arrhythmogenesis. $\mathcal{J}$ Mol Cell Cardiol 1981; 13: 699-704.

7 Parker JO, Chiong MA, West RO, Case RB. The effects of ischaemia and alterations of heart rate on myocardial potassium balance in man. Circulation 1970; 42: 205-17.

8 Dagenais GR, Marquis Y, Moisan A. Comparison of changes in myocardial balance of lactate, glucose, potassium and inorganic phosphate during pacinginduced angina. In: Roy P-E, Rona G, eds. Recent advances in studies on cardiac structure and metabolism. The metabolism of contraction. Baltimore: University Park Press, 1975; 10: 179-91.

9 Cobbe SM, Poole-Wilson PA. Catheter tip pH electrodes for continous intravascular recording. $\mathcal{F}$ Med Eng Technol 1980; 4: 122-5.

10 Webb SC, Canepa-Anson R, Rickards AF, PooleWilson PA. High potassium concentration in a parenteral preparation of glyceryl trinitrate: need for caution if given by intracoronary injection. Br Heart $\mathcal{F}$ 1983; 50: 395-6.

11 Kunze DL. Rate dependent changes in extracellular $\mathrm{K}^{+}$in the rabbit atrium. Circ Res 1977; 40: 105-11.

12 Martin G, Morad M. Activity-induced potassium accumulation and its uptake in frog ventricular muscle. $\mathcal{F}$ Physiol (Lond) 1982; 328: 205-27.

13 Laurent D, Bolene-Williams C, Williams FL, Katz LN. Effect of heart rate on coronary flow and cardiac oxygen consumption. Am $\mathcal{F}$ Physiol 1956; 185: 355-64.

14 Pitt B, Gregg DE. Coronary haemodynamic effects of increasing ventricular rate in the unanaesthetised dog. Circ Res 1968; 22: 753-61.

15 Maseri A, L'Abbate A, Pesola A, Michelassi C, Marzilli M, de Nes M. Regional myocardial perfusion in patients with atherosclerotic coronary artery disease, at rest and during angina pectoris induced by tachycardia. Circulation 1977; 55: 423-33.

16 Selwyn AP, Steiner R, Kivisaari A, Fox K, Forse G. Krypton-81m in the physiologic assessment of coronary artery stenosis in man. Am $\mathcal{F}$ Cardiol 1979; 43: 547-53.

17 Kléber AG. Extracellular potassium accumulation in acute myocardial ischaemia. $\mathcal{F}$ Mol Cell Cardiol 1984; 16: 389-94.

18 Shine KI, Douglas AM, Ricchiuti N. ${ }^{42} \mathrm{~K}$ exchange during myocardial ischaemia. Am $\mathcal{F}$ Physiol 1977; 232: H564-70.

19 Cobbe SM, Poole-Wilson PA. Continuous coronary sinus and arterial $\mathrm{pH}$ monitoring during pacing-induced ischaemia in coronary artery disease. Br Heart $\mathcal{f} 1982$; 47: 369-74. 